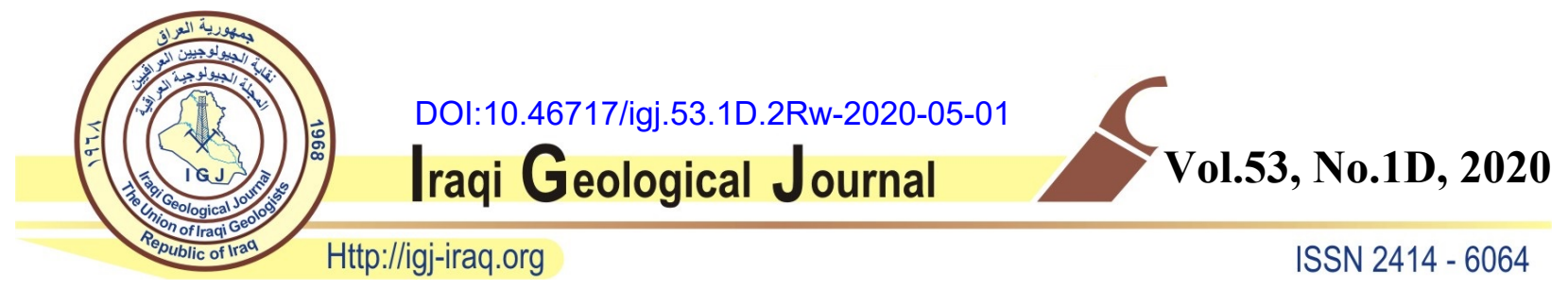

\title{
3D SEISMIC ATTRIBUTES INTERPRETATION OF ZUBAIR FORMATION IN AL-AKHAIDEIR AREA, SOUTHWESTERN KARBALA
}

\author{
${ }^{1}$ Kamal K. Ali* and ${ }^{1}$ Gassak F. Kadhim \\ ${ }^{1}$ Department of Geology, College of Science, University of Baghdad, Baghdad, Iraq \\ "E-mail: kkak1962@yahoo.com \\ Received: 15 January 2020; accepted: 21 March 2020
}

\begin{abstract}
This research includes interpretation of the seismic attribute of $3 D$ seismic data of Zubair Formation within Al-Akhadeir area southwestern Karbala to identify the structural and stratigraphic patterns and investigate the hydrocarbon accumulation by converting seismic data into the seismic attribute. The seismic attributes instantaneous phase, acoustic impedance and alterative automatic gain control were used. Application of the instantaneous phase reveals the mound configuration in addition to a flat spot which represents the seismic response of hydrocarbon-water contact, while shows lateral variation which reflects lateral facies variation in Zubair Formation. Faults, high stand tracts, low stand tracts were recognized indicating that Zubair facies are a clastic depositional system deposited in delta platform consisting of shallow-water, high energy marine (high stand tract). By acoustic impedance attributes indicate most likely, area of organic compound accumulation. Studying seismic attributes give evidence for the presence of hydrocarbon associated with phenomena such as mound, a flat spot within Zubair Formation.
\end{abstract}

Keywords: Seismic attributes; Reflection; Al-Akhadeir; Hydrocarbon; Zubair Formation

\section{INTRODUCTION}

Seismic attributes are quantities derived from seismic data to allow the user to make unconventional interpretation in the investigation of the reservoir characterization (Coren et al., 2001; Chopra and Marfurt, 2005). Seismic attributes improve the geological interpretation and subsurface image reflected by the seismic data (Taner, 2001; Chopra and Marfurt, 2005), these attributes could be applied on pre-stack such as amplitude versus offset (AVO) others applied on post stack seismic data (Brown, 2003). Seismic attributes can be measured by time, amplitude, frequency and attenuation or combinations of all these (Sarhan, 2017). Many studies concluded that seismic attributes are good tools to highlight seismic characteristic of interest (Chen and 
Sidney, 1997; Adero et al., 2017). Seismic attributes are controlled by phase, amplitude and frequency of the wavelet. Each one is helpful in a specific characteristic of the reflector and the reservoir. The attributes derived from the amplitude are used to improve the structural image of subsurface and to give more detail about the physical properties such as acoustic impedance and velocity, While the attribute phase is helpful in seismic stratigraphic interpretation, it reveals and examines the continuity in addition to the shape and geometry of the reflector. On the other hand, frequency derived attributes are suitable in providing an evaluation of the reservoir, helpful in stratigraphic event and fault interpretation and as direct hydrocarbon indicator (DHI) (Taner, 2001; Brown, 2003; Chopra and Marfurt, 2005).

The study aims to evaluate the Zubair Formation using seismic attributes as a tool in $3 \mathrm{D}$ seismic data interpretation in Al-Akhadeir area southwestern Iraq. The study area is located to the west of the Euphrates River (Fig. 1), It is of about $2042 \mathrm{Km}^{2}$. Al-Akhadeir area is greatly influenced by the movement of Arabian Plate to $\mathrm{N}$ and NE direction during multiple geologic times may product separate Arabian shelf from dipped Mesopotamia sediment and identify two parallel faults extending in NW-SE (Abu-jir) and NE-SW directions (Jassim and Goff, 2006).

The Zubair Formation was introduced by Glynn Tones in 1948 from Zubair oilfield and amended by Nasr and Hudson in 1953 (Bellen et al., 1959). The thickness of the formation in NE ranges 380-400 $\mathrm{m}$ of alternating shale; siltstone and sandstone, where it reaches up to $500 \mathrm{~m}$ in southern Iraq (Jassim and Goff, 2006). 2D seismic survey and interpretation of the results are executed by Mobil Company in 1980. The study showed the presence of anticline structural nose spreads enechlon with the structure of features Abu-jir area. Also, the existence of enclosures (it is believed they are drape fold type) separated by the influence of liquid. The study believed the appearance of reef deposited within Jurassic. According to Mobil Company's recommendations, Merjan-1 well, Al-Akhadeir-1, and west KF-1 were drilled but reef deposited and hydrocarbon indicators had not noticed in the area. Then, the exploration well Al-Akhadeir-2 (EK-2) was drilled in the studied area; the drilling reached $1859 \mathrm{~m}$ depth. The drilling result showed oil in many geological formations, the most important in Zubair Formation. Zubair Formation is the most significant formation of the Lower Cretaceous sequence in Iraq (Al-Sayyab,1989). The formation is assumed to represent a prograding delta originating from the Arabian Shield (Ziegler, 2001; Al-Zaidy, 2019). 


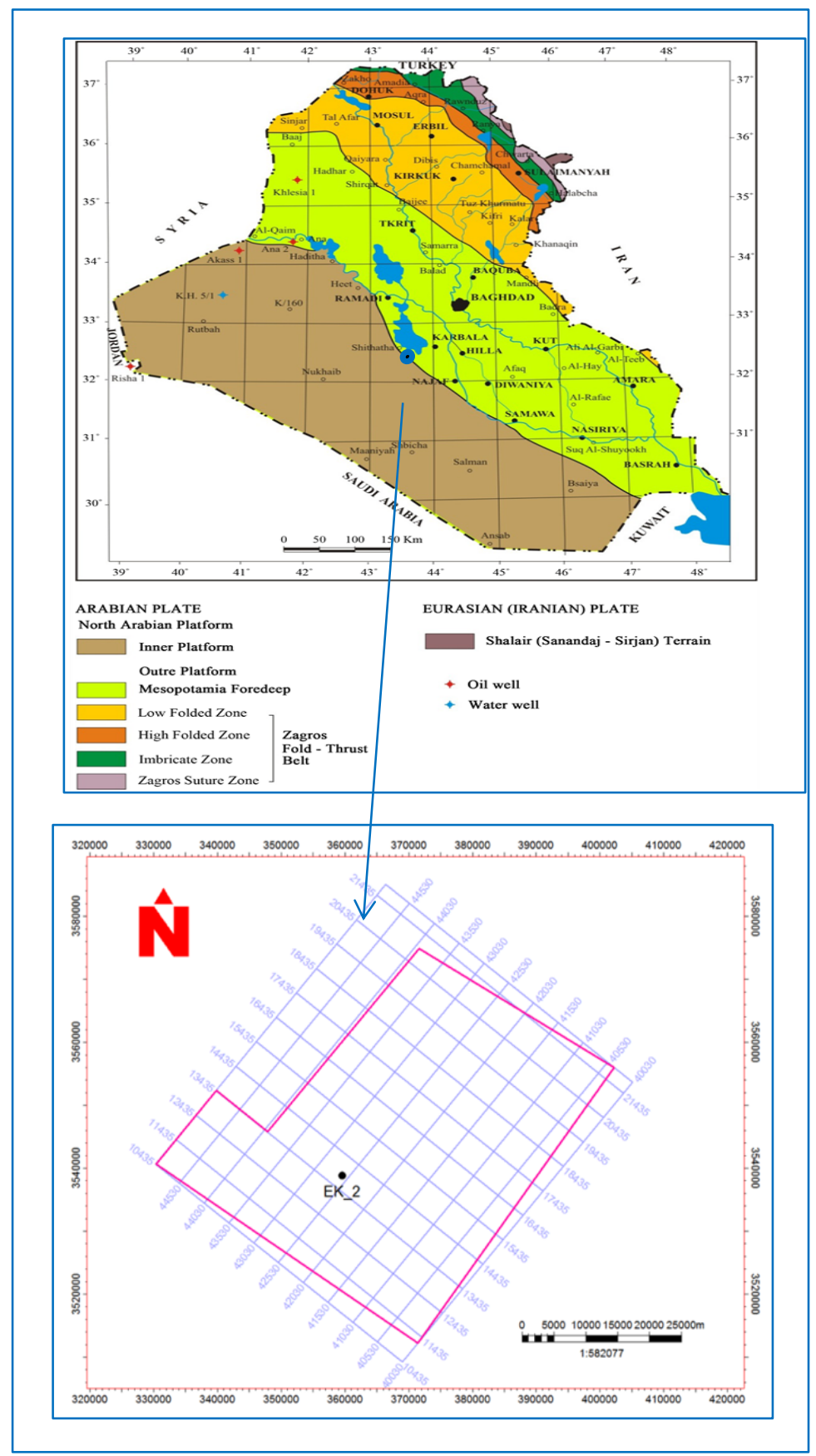

Fig. 1. Location map illustrates the base map of the study area

\section{SEISMIC DATA}

A 3D seismic reflection survey was conducted in the Al-Akhadeir area using a specific design to ensure ease execution with a good quality of recorded data. Before conducting the 3D survey project, the pre-planning report of the survey in the Al-Akhadeir area was prepared. A 3D, symmetrical split spread with vibrators source model Nomad 65 was achieved by the Oil 
Exploration Company (OEC) in 2017. The data was processed by OEC of the Ministry of Oil, Iraq using the OMEGA SPS software, version 2015.1. The interpretations are performed using the Petrel program.

\section{Description of the Used Programs and its Applications}

The interactive workstation petrel-2017 software offered by OEC was used to achieve the interpretation. The applications are used to:

\section{Seismic interpretation}

Through a building or drawing the reflectors that representing the top and the base of the Zubair Formation (make picking to these reflectors). This application contains a set of icons and every one of them has its own application.

\section{Volume attributes}

This application shows the properties in a seismic cube, in a statistical way, it arranges the information by amplitude and gives the converged points a certain color which tries to show what is hidden from the phenomena within the time cube.

\section{Seismic Attribute Section}

Extraction of the seismic attributes and their analysis enable to uncover earth science knowledge lined the data (Nanda, 2016). Seismic attribute technique is helpful to the seismic section of the study area to see DHI of traps, it's valuable within the interpretation of the seismic area subsequent to changing over to the unstable attributes data, by use of the following:

\section{Instantaneous phase}

The instantaneous phase is a seismic attribute used to depiction of the phase angle at any moment along a trace independent of amplitude. It exposes powerless and strong events with equal strength. Discriminator for geometrical shape great marker of continuities, angular unconformities, faults, pinch outs, sequence boundaries, on lap designs (Sheriff, 2002). The instantaneous phase section of the study area and the mound is noted by the application of the instantaneous phase section in addition to a flat spot which represent the seismic response of hydrocarbon-water contact (Fig. 2).

\section{Alterative AGC}

Alterative automatic gain control (AGC) is a system in which the output amplitude is utilized for automatic control of the gain of an amplifier. Seismic amplifiers used to have individual AGC for each channel, although multichannel control was here and there utilized. 
AGC utilizes a feedback loop whereby the output level controls the gain so as to keep the output level within certain limits, but the information contained in the variable gain is apt to be lost (Onajite, 2014). Figure (3) represents the AGC of the instantaneous amplitude section of inline 43769 within the study area shows the influence of the faults in the area.

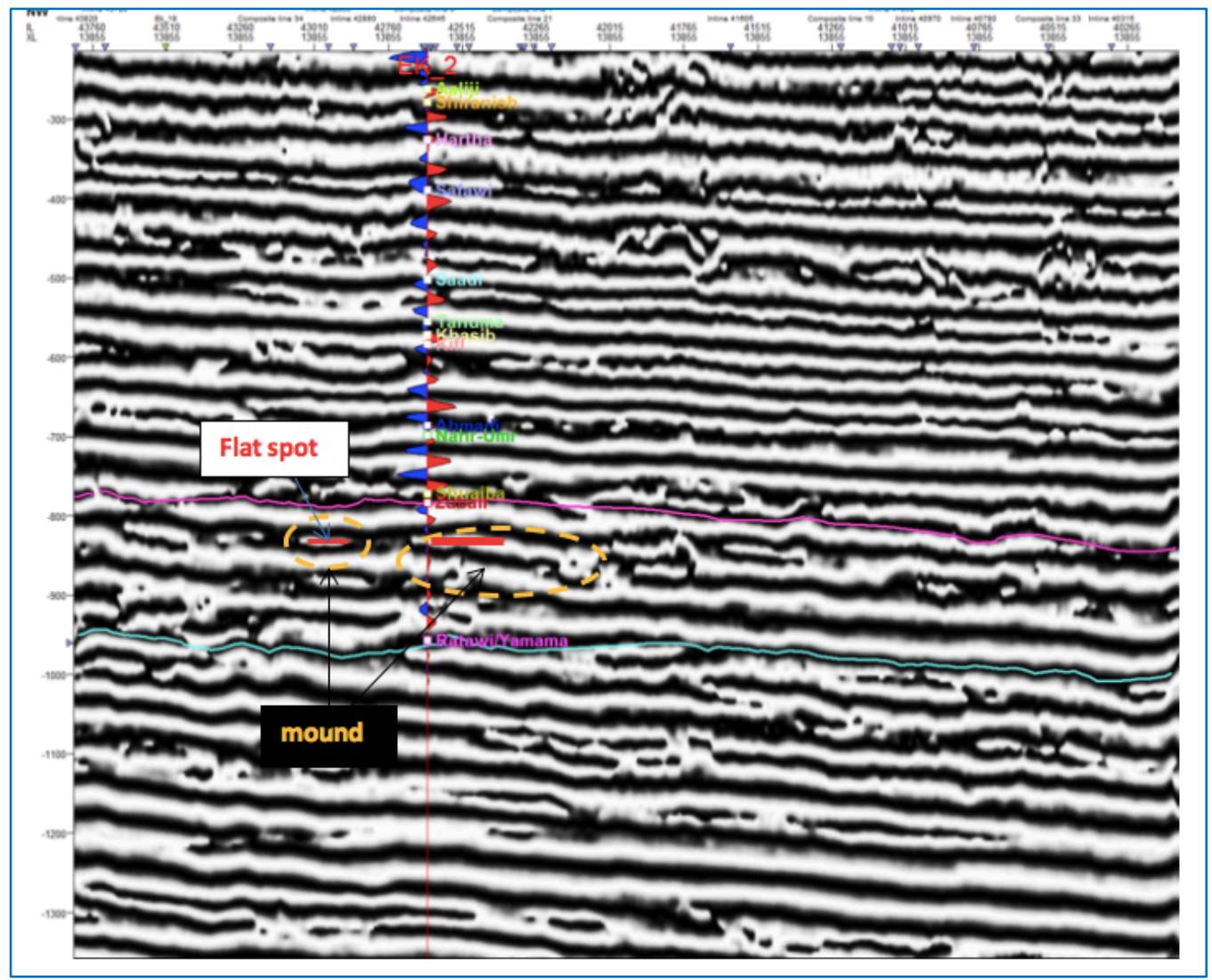

Fig. 2. Instantaneous phase 3D seismic section of the study area (xnline 13855) shows flat spots features through mound seismic facies in Zubair Formation

The section reveals lateral varieties in the reflection quality in the NW part within Zubair Formation which demonstrate of changes in lithology, proposing flow might exist in this part of the considered reflectors, or might be hydrocarbon combination as alludes in the area by high stand tract (HST) and low stand tract (LST). Then again, the continuous changes may because of the lateral change in the facies and bed thickness inside the Zubair Formation. The slight changes in the thickness are attributed to the paleotopography of the basin.

\section{3-Acoustic impedance}

The acoustic impedance is a significant property of the rock layer, since it decides the reflection reaction of the formation rock. In the earth, reflections happen at the interfaces among layers and the reflection amplitudes depend, for the most part, on the distinction of acoustic impedance from 
layer to other. Reflected abundance is the distinction between the two impedances of each layer isolated by their aggregate (SOC, 1988). Low amplitude value (black dashed polygon) is discovered in the study area that indicates most likely, area of organic compound accumulation (Fig. 4).

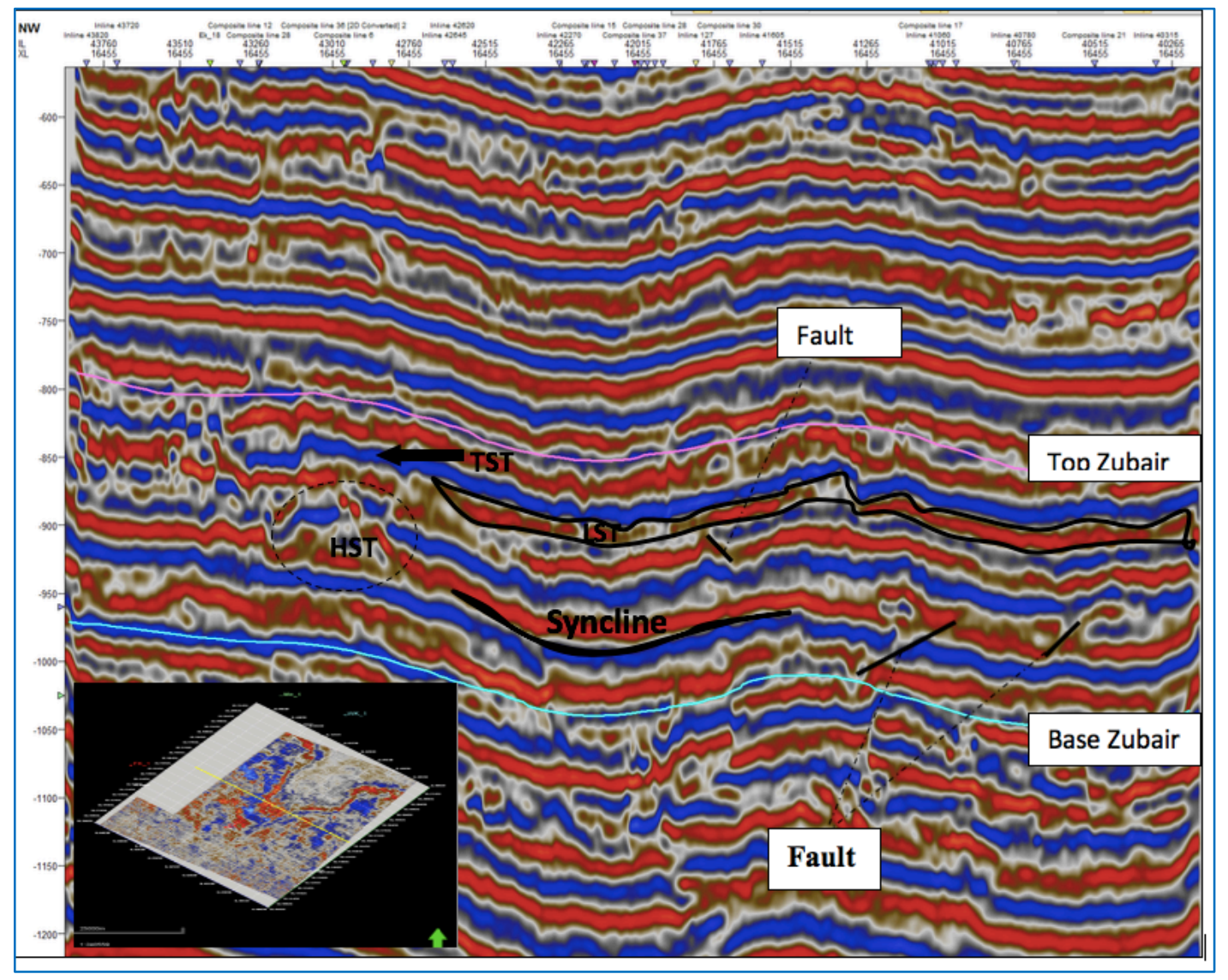

Fig. 3. The AGC section in the study area (inline 43769)

\section{Discussion of Zubair Formation and Hydrocarbon Accumulation}

Zubair Formation is the hugest sandstone store in Iraq made out of fluvio-deltaic, deltaic and marine sandstones (Jassim and Goff, 2006). It is made out of alternating shales and sandstones with specific siltstones. The assortment in lithology gives some regularity, towards the shore; the measure of the pelitic segments quickly diminishes. In the west, the development is gathered for the most part of sands as it were. Towards the bowl the formation contains an ever-increasing number of shales and turns out to be absolutely shaley close to the east area (Jassim and Goff, 2006). Zubair Formation represents delta platform facies comprising of shallow-water, highenergy marine (delta-front) sandstone, shale delta plain shale, channel-fill sandstones and wide spread coal or lignite beds. The last maybe was the source rocks which created the kerogen and 
later oil in Zubair Formation (Jassim and Goff, 2006). Sands identified with channels normally keep stores for hydrocarbons. Therefore, the discovery of stations in the seismic section in the study area is a significant piece of seismic interpretation for oil and gas investigation (Fig 5).

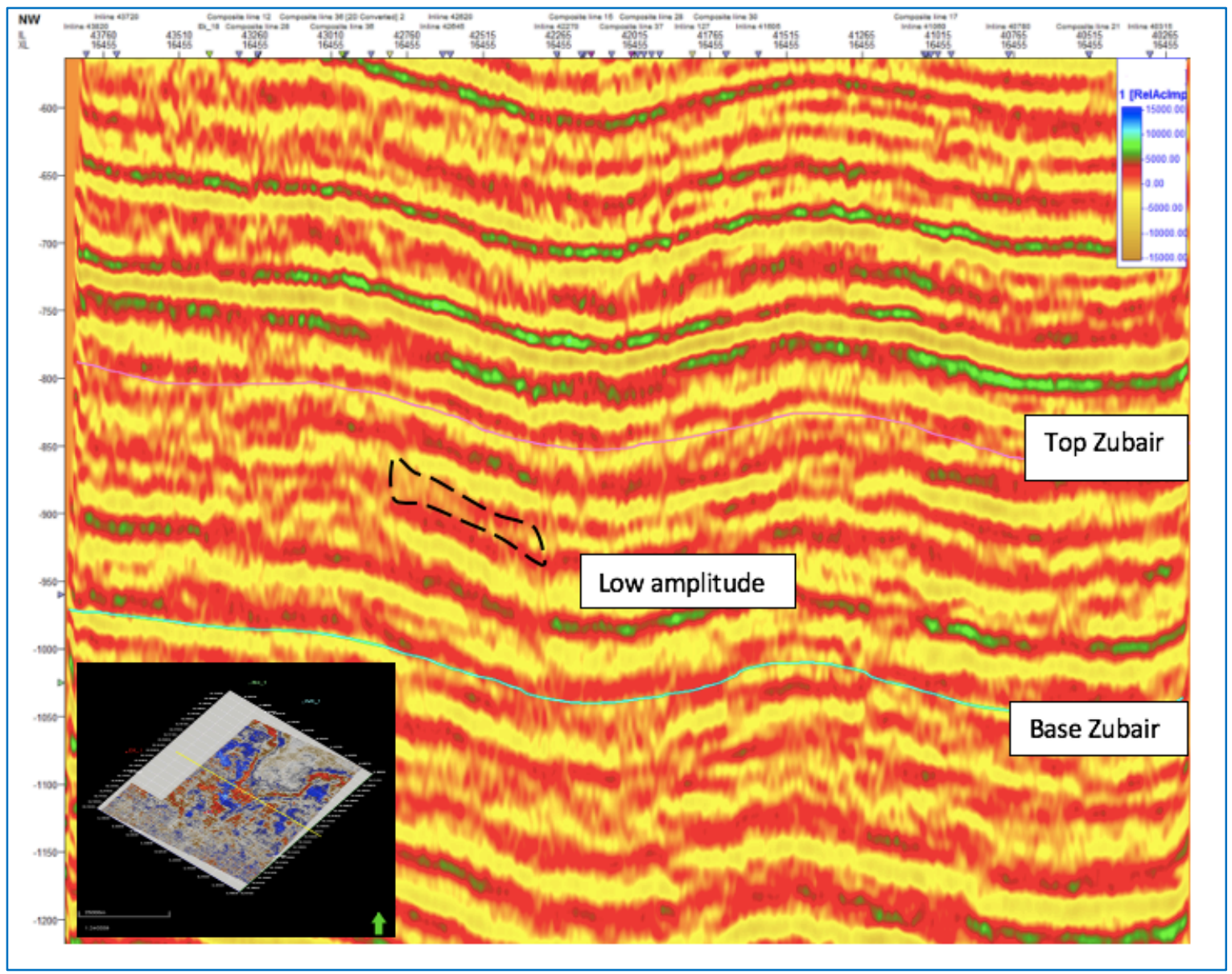

Fig. 4. The relative acoustic impedance (inline43760)

Relative sea level fall, sub aerial erosion took place on the outcropping rack making an erosional surface with regular channel fill geometry. Afterward, when relative ocean level rose thickest sands are normally restricted to a relative narrow channel (Fig 5).

Mounded reflection arrangements are interpreted as strata-framing heights rising the general degree of the encompassing strata. Most hills in the clastic rocks (Zubair Formation) are deposited on slope or basins. Zubair Formation is interpreted as three depositional sequences representing high stand systems tracts, which indicate to shelf margin platform due to sea level fall, this regarded promising reservoir. According to seismic parallel facies and channels the area represents delta front of delta extending toward the east of the study area. These results corresponding with previous studies such as Al-Rubaye et al., 2019 and Al-Zaidy, 2019. 


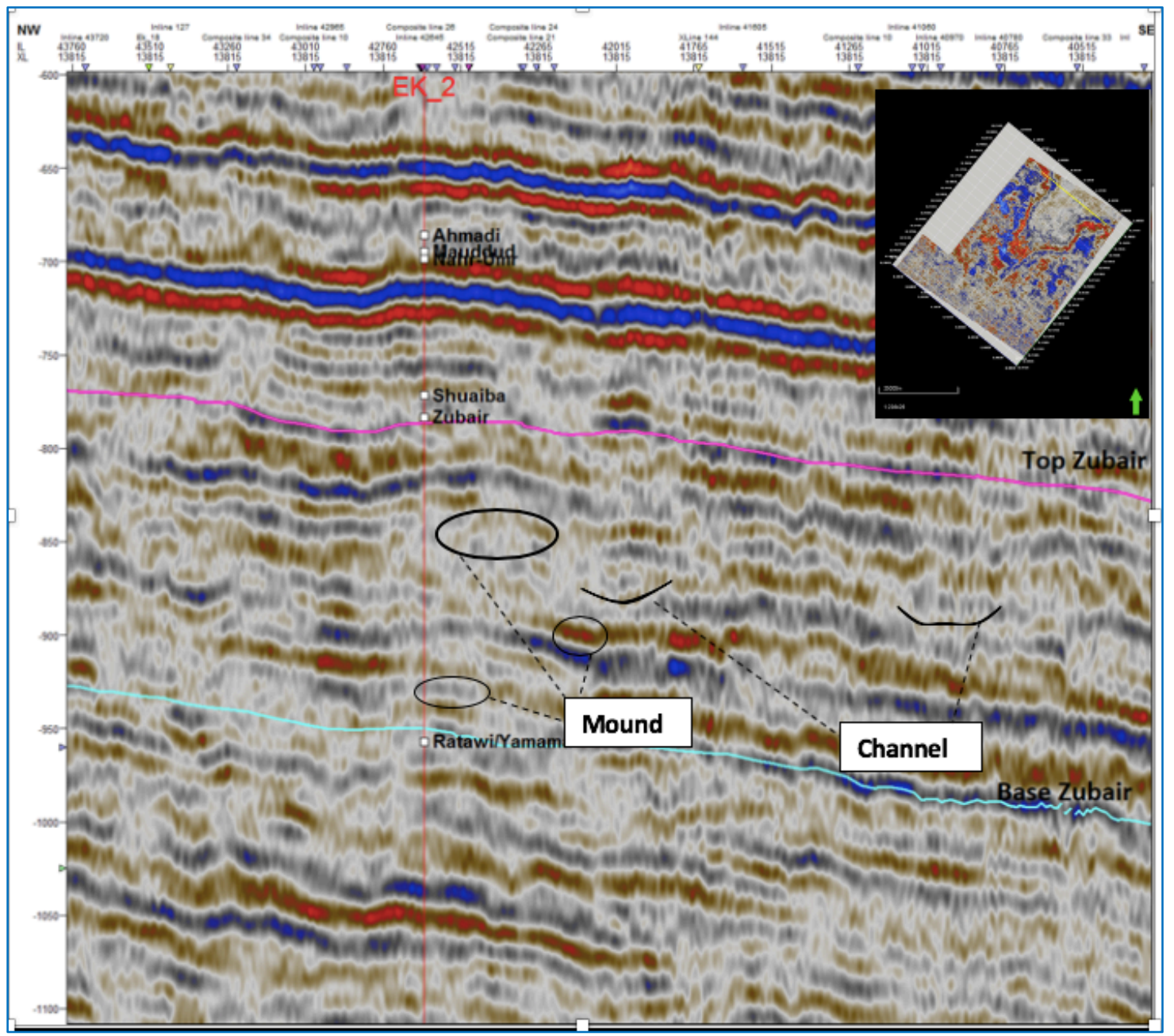

Fig. 5. Seismic section shows channel and mound (inline 43760)

\section{CONCLUSIONS}

1. Seismic attributes techniques were applied to the seismic data in the current research which include the instantaneous phase, alterative AGC and acoustic impedance. The seismic composite attributes (instantaneous phase attribute) have applied so as to clarify the DHI. Using this system support to identify the DHI for organic compound accumulation and haven't been previously identified. Seismic reflection facies mound and flat spot configuration has been identified which indicate hydrocarbon-water contact.

2. Mainly the strata units of Zubair Formation are horizontal with some stratigraphy and structure phenomena. Zubair facies are clastic depositional framework deposited in delta platform, Zubair represents delta plate from facies comprising of shallow - water, high energy marine (delta sandstone, channel fill sandstone). Facies have progradational 
configuration (sigmoid) subjected to truncation erosion to stream onlap carbonate platform surface. Some indications suggest depositional channel which represents the trend of sediment influx from basin toward continental, others pattern from HST to the margin of the shelf insulting of sigmoid within the transgression stand tract deposited on the surface boundaries within the Zubair Formation.

3. Zubair Formation is interpreted as three depositional sequences representing high stand systems tracts, which indicate to shelf margin platform due to sea level fall, this regarded promising reservoir. According to seismic parallel facies and channels the area represents delta front of delta extending toward the east of the study area.

\section{REFERENCES}

Adero, B., Masinde, A, and Osukuku, G., 2017. Using Seismic Attributes for Reservoir Characterization Conference Paper. 2017 Oil, Gas \& Mines Africa, Exhibition and Conference (OGMA) 9-11 May 2017, Nairobi, Kenya.

Al-Rubaye, H. H., Gayara, A. D., Al-Zaidy, A. A, 2019. Facies Analysis and Stratigraphic Development of the Zubair Formation in the Mesopotamian Zone, Southern Iraq. Iraqi Journal of Science, 2019, 60(2):290-307.

Al-Sayyab, A.,1989. Geology of Petroleum. University of Baghdad Press, Baghdad, 472P.

Al-Zaidy, A. A., 2019. Facies Analysis and Sequence Stratigraphy of the Zubair Formation in the Kifl oilfield, Central of Iraq, Iraqi journal of Science, 60(2): 341-352.

Bellen, R. C., Van, H. V., Dunnington, Wetzel, R. and Morton, D., 1959. Lexique Stratigraphique International. Asie,Fase 10, Iraq, Paris.

Brown, A. R., 2003. Interpretation of Three-Dimensional Seismic Data, AAPG Memoir 42, 3rd ed., Tulsa, Oklahama, 368 P.

Chen, Q., Sidney, S., 1997. Seismic attribute technology for reservoir forecasting and monitoring. Lead. Edge 16:445-456.

Chopra, S., Marfurt, K. J., 2005. Seismic attributes - A historical perspective. Geophysics, 70 (5):3SO-28SO.

Coren, F., Volpi, V., Tinivella, U., 2001. Gas hydrate physical properties imaging by multi-attribute analysis-Blake Ridge BSR case history. Mar. Geol., 178 (1):197-210.

Jassim, S. Z., and Goff, J. C., 2006. Geology of Iraq, Dolin Prague and Moravian Museum, Brno, 341p.

Nanda, N. C., 2016. Seismic Data Interpretation and Evaluation for Hydrocarbon Exploration and Production, Cuttack, Odisha, India, 224 p.

Onajite, E., 2014. Seismic Data Analysis Techniques in Hydrocarbon Exploration, British Library Cataloguing in Publication.

Sarhan, M. A., 2017. The efficiency of seismic attributes to differentiate between massive and non-massive carbonate successions for hydrocarbon exploration activity, NRIAG Journal of Astronomy and Geophysics, 6(2):311-325.

Sheriff, R. E, 2002. Encyclopedic Dictionary of Applied Geophysics, 4th Ed., SEG, 13 Geophysical References Series, $429 \mathrm{p}$.

SOC, 1988. Final geological report of WKf-1 well, South Oil Company,19P.

Taner, M. T., 2001. Seismic attributes. Canadian Society of Exploration Geophysicists Recorder, September,49-56.

Ziegler, M., 2001. Late Permian to Holocene Paleofacies evolution of the Arabian Plate and its hydrocarbon occurrences, GeoArbia, 3:445-504. 